\title{
The management of the international student experience in the South African context: The role of sociocultural adaptation and cultural intelligence
}

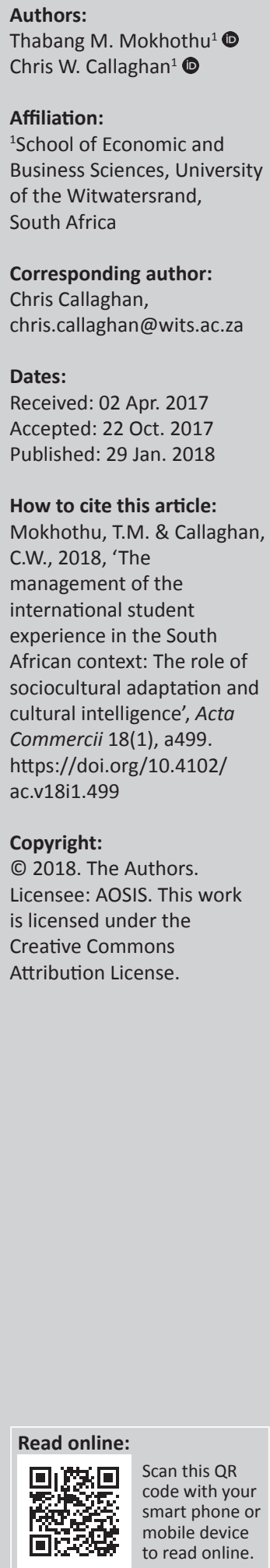

Orientation: Sociocultural adaptation and cultural intelligence theory predicts certain relationships between these two orientations and performance in culturally diverse contexts.

Research purpose: The aim of the research was to investigate the contribution of cultural intelligence to sociocultural adaptation and the role of cultural intelligence as a mediator of the relationship between sociocultural adaptation and academic performance of international students in the context of a large South African university.

Motivation of the study: The study was motivated by a lack of knowledge of the role of cultural intelligence in its contribution to sociocultural adaptation and academic performance of international students in the current South African academic context. This lack of knowledge was taken to be a problem for managers in the higher education context.

Research design, approach and method: A purposive sample of 263 international students from a large South African university was analysed using confirmatory factor analysis and multiple linear regression analysis.

Main findings: Unlike metacognitive, cognitive and behavioural cultural intelligences, only motivational cultural intelligence, together with sociocultural adaptation, was found to be significantly and positively associated with academic performance.

Practical and managerial implications: Given that motivational cultural intelligence reflects the interest and motivation of an individual to learn about and adapt to other cultures, university managers should seek to cultivate motivational cultural intelligence through university activities, as this orientation can be developed in sojourners.

Contribution or value-add: The results of this study contest broader predictions that all cultural intelligence orientations act equally to enable academic performance in this context.

\section{Introduction}

Within the year 2013, South African universities saw close to 74000 international student (undergraduate plus postgraduate) enrolments, which accounted for nearly $8 \%$ of the student body; of these, $15 \%$ of postgraduate students were international, with international students comprising only $6 \%$ of the undergraduate cohort (ICEF Monitor 2013). With the world experiencing rapid globalisation, knowledge of relationships around intercultural education has become increasingly important (Andrade 2006). Graduate employees with intercultural knowledge and the requisite knowledge and skills essential to work in the modern knowledge environment underpin organisational success. Within the globalised economy, their competencies are in high demand across industries (Council of Higher Education 2009). In their initial adaptation to host countries and the university experience, however, international students face certain unique challenges not experienced by host country students (Westwood \& Barker 1990). Given these challenges, and the rising importance of cultural adaptation (CA) to universities in an increasingly globalised world of higher education, this study seeks to investigate the relationships between sociocultural adaptation (SA), cultural intelligence (CI) and academic performance of international students from other countries, or sojourners, in the context of a large developing-country university.

Long-standing literature relates CI to psychological (e.g. an individual's well-being, adjustment and satisfaction), behavioural (such as the ability to develop social networks and intercultural cooperation) and performance outcomes (for instance task, contextual performance and leadership effectiveness) (Ang et al. 2004; Leung et al. 2014). Importantly, CI is not static but can be nurtured 
to support the attainment of these and other outcomes. CI is pliable and can be developed through cross-cultural experiences, experiential learning training and internal processing (Bhawuk, Sakuda \& Munusamy 2008; Leung et al. 2014; Williams \& Johnson 2011). However, what has not been sufficiently considered in this literature is the extent to which CI contributes to SA and sojourner academic performance in this context.

Institutions that do not cater to the unique needs and requirements of international students may leave students feeling disappointed, unfulfilled and in certain instances exploited (Sherry, Thomas \& Chui 2010). Of late, increasingly mobile international students are choosing South Africa as a destination for the purpose of higher education. A report published by France (2013) found that out of 380376 students from Africa who chose to study abroad (a total which represents approximately $10 \%$ of international students globally), South Africa took the second position with regard to the preferred destination of international students, with a $15 \%$ market share, whilst France remained the leading destination with $29.2 \%$ of sojourners electing to study there. A $28.8 \%$ increase in market share has been experienced by South Africa since 2006, whilst France experienced a 1\% decrease within the same time period.

People are constantly redefining themselves through interactions with a multitude of individuals from distinguishable and diverse intercultural settings and situations, including those related to family, colleagues, friends, religious groups and leisure activities (Ang et al. 2007). CI is widely considered an important facet of the intercultural competence of an individual (Ang et al. 2007; Leung et al. 2014) and is therefore key to understanding SA.

Absent from this body of literature, however, is knowledge of the extent to which CI contributes to SA and, more specifically, knowledge of which particular aspects of CI are relatively more important in this contribution is lacking in this context. Knowledge of the relative contributions of subordinate aspects of CI to SA would allow for better support of sojourners in this context. Further, the contributions of $\mathrm{CI}$ and SA to international student performance seems little understood in this context. Knowledge of the extent to which global theory generalises to this context is important, given certain characteristics of the contemporary South African context which differ markedly from those of other global contexts. This article seeks, therefore, to test theory predicting the contribution of CI to SA and the contributions of both CI and SA to international student academic performance in the context of a large South African university. Although the impact of globalisation has resulted in the world seeming 'smaller' in various ways (Friedman 2005), the increased cultural diversity generates new issues for people and institutions (Ang et al. 2007). However, research that places a focus on factors that could improve the intercultural encounters of international students in a South African context is relatively scarce (Gelfand, Erez \& Aycan 2007).
In particular, literature related to an individual's capabilities of intercultural effectiveness is sparse and unsystematic in nature; this leaves a crucial gap in understanding the reasons why some individuals perform more effectively within culturally diverse situations than others (Ang et al. 2007). Although there have been various studies that examine the effects of sociocultural differences on the adjustment of sojourners globally (see Ward \& Kennedy 1993), the literature lacks analysis from an African perspective, and more specifically, from a South African contextual perspective. Research on CI and its relation to the adjustment of international students in the contemporary South African context is lacking. Arguably, this research is particularly important in a context that is experiencing an increase in international students.

The article proceeds as follows. First, theory is introduced, and hypotheses are derived from the literature. Next, the methods applied in the study are introduced. The results are then reported and discussed. Finally, conclusions and recommendations for further research are presented. Literature and theory are now discussed.

\section{Literature review and hypothesis formulation}

International students are individuals who come from different countries with diverse religious beliefs and political structures; yet these individuals share similar situations as international students, allowing them to be grouped and identified as one (Misra \& Castillo 2004). People in various cultures have different goals, leading to the formation of distinctive cultural norms that assist that particular group of individuals towards the achievement of those culturally defined goals (Brislin, Worthley \& Macnab 2006). There are various challenges that international students may face during the cross-cultural adaptation process. These include finding accommodation, learning the education system and academic culture of the country, and developing new friendship groups, a process which is related to formulating a new social support system (Poyrazli \& Grahame 2007). The most notable challenge faced by international students, however, comes from making successful intercultural transition whilst remaining centred to their academic objectives (Chen 2009; Cushner \& Karim 2004; Gelfand et al. 2007; Lin, Chen \& Song 2012).

These adaptation challenges vary however. Literature suggests a number of factors can have an effect on the adaptation process, including demographic factors (i.e. age, country of origin, gender, children, marital status), individual factors (i.e. previous international exposure, language competency levels, students' goals, personality characteristics, such as sensitivity, academic self-efficacy assertiveness and flexibility) and contextual components (i.e. resource availability, whether the individual has a social support network and levels of racial and ethnic diversity on campus) (Ang et al. 2007; Ward \& Kennedy 1999; Yang, Noels \& 
Saumure 2006). Resource scarcity can also pose challenges to adaptation (Papageorgiou \& Callaghan 2014).

When individuals migrate to unfamiliar cultural settings, they usually experience adjustment issues such as stress because of the norms and behaviours they are exposed to which are unfamiliar and confusing to them. The literature on intercultural encounters has shown the centrality of SA (Ang et al. 2007; Wilson 2011) to intercultural experiences. Cultural adaptation consists of two aspects, namely the sociocultural sense of adjustment and psychological feelings of well-being (Searle \& Ward 1990; Ward \& Kennedy 1996). According to Shaffer et al. (2006), CA is considered to be an effective outcome as it exhibits subjective assessments, and these subjective assessments have affective implications (Ang et al. 2007). The definition of cross-cultural adjustment used in this study can be stated as follows: 'the degree of psychological comfort and familiarity that the individual has for the new environment', following Black (1990:111). This approach reconceptualises 'culture shock', whilst at the same time also considering both the affective and social components of the intercultural experience, permitting an assessment of adjustment or maladjustment that arises as a result of the transition experience (Earley \& Ang 2003; Wang et al. 2015; Ward, Wilson \& Fischer 2011). Ang et al. (2007) stress that cross-cultural adjustment can be associated with $\mathrm{CI}$, as the various dimensions of $\mathrm{CI}$ have an essential impact on one's work environment, interactions with host-nationals and general living conditions (Kodwani 2012; BhaskarShrinivas et al. 2005; Lin et al. 2012; Wang et al. 2015). Studies conducted by Chirkov et al. (2007) have shown that greater levels of CI can lead not only to enhanced academic performance but also to greater subjective well-being within international students, and could also be used as an estimation of their psychological adaptation and SA over a period of time (Lin et al. 2012; Ward et al. 2011). According to this literature, $\mathrm{CI}$ can enable SA, and can also enable academic performance through its influence on SA. In other words, it not only contributes to SA directly, but SA may mediate the influence of CI on academic performance of international students. These relationships are now considered further in relation to the literature.

Literature has previously viewed intelligence in a linear manner as the ability to problem solve in a scholastic setting, but there has been an increasing consensus that the concept of intelligence may also be shown in alternative situations than educational (Ang \& Van Dyne 2015; Kurpis \& Hunter 2016). Cultural intelligence recognises the phenomenon that is globalisation (Earley \& Ang 2003; Malek \& Budhwar 2013) and its relationships with enculturation. CI is a distinguishable form of intelligence that is focused on an individual's ability to grasp reason and behave in an effective manner in scenarios typified by cultural diversity (Ang \& Van Dyne 2015; Schreuders-van den Bergh \& Du Plessis 2016). A prominent topic in the cross-cultural literature is the importance of cooperation, harmony and having good relations with others whilst considering cultural discrepancies and other issues with cultural integration (Brislin et al. 2006). Knowledge of cultural adjustments is important in order to be able to operate effectively in a new cultural setting (Brislin et al. 2006; Callaghan 2015; Hofstede 2001).

People can familiarise themselves with other cultures in multiple ways. Some cultural exposures, however, may be more significant than others, such as being exposed to another culture at a young age, that is, a child who migrates with their parents to an international assignment, or being a spouse of the sojourner (Crown 2008; Lam \& Selmer 2004). Individuals who have high levels of CI possess 'a strong mastery and sense of emotional display and physical presence' (Earley, Ang \& Tan 2006:34). CI incorporates four facets, namely metacognitive, cognitive, motivational and behavioural (Earley \& Ang 2003).

\section{Metacognitive cultural intelligence}

Metacognitive CI is defined as a person's control over their cognitions that allows for deep information processing in relation to culture, which incorporates cognitive strategies adopted for the acquisition and generation of coping strategies (Flavell 1979; Rose et al. 2010). Individuals who have higher levels of metacognitive CI are typically consciously aware of others' cultural preferences beforehand and whilst interacting with them. These individuals also query different cultural assumptions, which leads them to adjust their cognition during and after interactions (Ang et al. 2007; Brislin et al. 2006; Kodwani 2012), and also in relation to job performance and cultural judgement with regard to decision-making tasks (Ang et al. 2007). Therefore, it is expected that high metacognitive CI will lead to higher levels of cross-cultural adjustment (Huff, Song \& Gresch 2014). Individuals with higher levels of metacognitive CI have been observed to know when and how to apply their cultural knowledge (Ang et al. 2007). Therefore, they have a better understanding of the expected social cues in settings defined by cultural diversity (Triandis 1994). Given that SA can enable academic performance for international students, the specific contributions of different dimensions of CI to SA are considered important knowledge, as is the extent to which each of the dimensions of CI contributes both directly and indirectly to academic performance. On account of this literature, the following hypotheses are derived:

Hypothesis 1.1: That metacognitive cultural intelligence is positively and significantly associated with sociocultural adaptation.

Hypothesis 2.1: That metacognitive cultural intelligence is significantly associated with academic performance.

Hypothesis 3.1: That sociocultural adaptation mediates the relationship between metacognitive cultural intelligence and academic performance of international students.

The latter hypothesis posits that SA is the channel through which metacognitive CI contributes to academic performance. 


\section{Cognitive cultural intelligence}

Cognitive CI refers to an individual's knowledge of the customs, norms and conventions that exist within various cultures (Earley \& Ang 2003; Huff et al. 2014; Rose et al. 2010). Whilst metacognitive CI places an emphasis on higher-order cognitive processes, cognitive CI relates to the knowledge of the conventions, practices and norms associated with different cultures, which may be obtained from personal and academic experiences. This may include the knowledge of the legal, social and economic systems of various cultures and subcultures (Earley \& Ang 2003; Rose et al. 2010; Triandis 1994) and also the knowledge of basic frameworks of cultural values (such as Hofstede 2001). People who have greater levels of cognitive CI have the ability to understand and distinguish between the similarities and differences across different cultures (Brislin et al. 2006; chen, Wu \& Bian 2014; Huff et al. 2014). According to Ang et al. (2007), cognitive CI improves decision-making when individuals partake in cross-cultural interactions (Ang et al. 2007; Huff 2013; Huff et al. 2014; Ward et al. 2009). From this literature, the following hypotheses are derived according to the logic explained in the previous section:

Hypothesis 1.2: That cognitive cultural intelligence is positively and significantly associated with sociocultural adaptation.

Hypothesis 2.2: That cognitive cultural intelligence is significantly associated with academic performance.

Hypothesis 3.2: That sociocultural adaptation mediates the relationship between cognitive cultural intelligence and academic performance of international students.

\section{Motivational cultural intelligence}

Motivational $\mathrm{CI}$ is related to the motivation behind cognitive processes and cognitive knowledge, referring to the will and desire to adapt to the diversity associated with new cultural settings (Crowne 2013; Earley \& Ang 2003; Ng \& Earley 2006; Rose et al. 2010). A positive relationship exists between crosscultural adjustment and motivational $\mathrm{CI}$ as individuals with a high level of motivational CI may be more interested in other cultures and therefore might have a greater possibility of succeeding within various cultural settings (DeNisi \& Pritchard 2006; Eccles \& Wigfield 2002; Templer, Tay \& Chandrasekar 2006; Stone-Romero, Stone \& Salas 2003). Individuals higher in CI may therefore be more likely to invest the required energy and attention in cross-cultural settings. Intrinsic motivation (Deci \& Ryan 1985) and a person's self-assurance in their effectiveness whilst in a crosscultural setting (Bandura 2002) can contribute to better SA. Research has corroborated that motivational CI has the ability to predict interaction, work and general adjustment of sojourners (Ang et al. 2004, 2007; Templer et al. 2006; Ward \& Fischer 2008). Accordingly, the following hypotheses of international students are offered:

Hypothesis 1.3: That motivational cultural intelligence is positively and significantly associated with sociocultural adaptation.

Hypothesis 2.3: That motivational cultural intelligence is significantly associated with academic performance.
Hypothesis 3.3: That sociocultural adaptation mediates the relationship between motivational cultural intelligence and academic performance.

\section{Behavioural cultural intelligence}

Behavioural CI as a dimension of CI involves the capability to engage in adaptive behaviours in accordance with cognition and motivation based on cultural values of the specific cultural settings (Ramsey \& Lorenz 2016; Rose et al. 2010). People use impression management techniques so that they may be viewed positively by others (Ang et al. 2007; Mendenhall \& Oddou 1985). Meta-analytic findings suggest that self-efficacy and the ability to build relationships can both predict sociocultural adjustment (Ang et al. 2007; Bhaskar-Shrinivas et al. 2005). Bandura's (2002) social cognitive theory argues that individuals who initiate effort, and demonstrate persistence in their efforts, can improve performance in tasks. Similarly, Epel, Bandura and Zimbardo (1999) have shown that higher efficacy beliefs can lead to higher engagement levels and persistence in challenging situations, as well as greater levels of adjustment (Ang et al. 2007). Behavioural IC is expected to relate positively to academic performance, as individuals with high levels of this dimension typically adjust their verbal and non-verbal behaviours to fit other people's expectations (Ang et al., 2007; Shaffer et al. 2006). On the basis of this literature:

Hypothesis 1.4: That behavioural cultural intelligence is positively and significantly associated with sociocultural adaptation.

Hypothesis 2.4: That behavioural cultural intelligence is significantly associated with academic performance.

Hypothesis 3.4: That sociocultural adaptation mediates the relationship between behavioural cultural intelligence and academic performance of international students.

\section{Sociocultural adaptation}

There are other factors that influence the SA and academic performance of international students. The level of a person's exposure to different cultures may be based on the amount of time spent outside of a country of origin, the number of countries visited, how culturally distinctive visited countries are from the individual's own cultural background and the extent to which the person desires to experience the new culture during a visit (Crowne 2013). A person learns that intercultural experiences are distinguishable from ordinary experiences, and this knowledge becomes integrated into a person's thought processes and perception (Earley \& Peterson 2004). Individuals have the ability to 'learn to select and apply the appropriate tools, adapting them when necessary' (Johnson, Lenartowicz \& Apud 2006:534) when they are exposed to other cultures different to theirs.

Through networking within a different culture, one may be influenced by the culture, which will in turn influence the knowledge and understanding that one has about that particular culture, and how it is dissimilar to one's own (Crowne 2008). According to Phillion (2002), a person can 
educate themselves about the proper behaviour required within a particular culture through interactional observation and experiencing new cultural situations. When individuals travel abroad, they gain knowledge on what is considered culturally appropriate within their new context, and cultural exposure can positively influence $\mathrm{CI}$ through the development of cultural understanding (Crowne 2008). When considering the social learning perspective, people who engage in highly cross-cultural experiences have a higher likelihood of retaining and reproducing the attained competence and behaviours (Caligiuri \& Tarique 2009). Given constraints to SA might constrain an international student's ability to develop support networks and pose challenges to effective adjustment, SA is considered to be an important enabler of academic performance. Hence, it is proposed that:

Hypothesis 4: Sociocultural adaptation is significantly associated with academic performance.

The literature has shown experiential learning as an important contributor to the development of CI (Crowne 2008; MacNab 2012). Crowne (2008) found people who travelled to more foreign destinations for either employment or education purposes had higher levels of cognitive and behavioural CI (Crowne 2008). Given that the time spent immersed in a cultural context can therefore be key to SA, a measure of years spent in the country was included in the analysis. Cultural norms have been found to differ across societies and cultures with regard to gender (Hofstede 2001), and a measure of gender was included in the analysis for this reason. Similarly, age, language ability and numbers of dependent children were also included as covariate factors in the estimation process. Having reviewed theory that relates the variables under study, the methods applied are now introduced and discussed.

\section{Methodology}

This research was located within the paradigm of postpositivism (Healy \& Perry 2000; Hunt 1991), which recognises the shortcomings of positivism but applies positivist principles to research practice. Positivism recognises the validity of causal explanations and fundamental laws and empirical testing of theory (Amaratunga et al. 2002; Remenyi, Williams, Money \& Swartz 1998), drawing from an ideology of deductivisim, which assumes that valid inferences made from a finite set of events in the past can be used to make predictions of future events (Amaratunga et al. 2002). This design was taken to be appropriate for this particular study as it allowed for statistical testing of theory.

\section{Sampling and data collection}

The sample of sojourners in the study was obtained through the use of purposive sampling, which can be described as a person's use of judgement and deliberate effort to include a certain collective of people who meet specified criteria in their sample (Kerlinger 1986). A sample of 263 international students was drawn through a combination of convenience and snowball sampling with students from different countries and regions currently studying at the university under study.
Students born in South Africa but who had migrated to another country at a young age were also considered as sojourners for the purposes of this study. The sample was made up of 94 female students (36\%) and 169 male students (64\%), with their age ranging from 18 to 58 . A large proportion (40\%) consisted of sojourners between the age of 19 and 22. As shown in Table 2, most of the students came from Africa (84.29\%), with the most prominent countries being Nigeria (18.6\%), Zimbabwe (33.8\%), Lesotho (4.9\%) and Congo (4.2\%). A total of $55 \%$ of the students were currently studying an undergraduate degree, whilst the other $45 \%$ comprised postgraduate students. Master's students comprised $19 \%$ of the sample. A large percentage of the students $(29.7 \%)$ were from the school of Economic and Business Sciences, whilst $17.8 \%$ of the students came from Medical Sciences and 17.7\% from the School of Engineering. With regard to accommodation, $39.6 \%$ of sojourners resided in the accommodation provided by the university, $54 \%$ lived outside of the university but within Johannesburg and 6.5\% reported residing outside of the City of Johannesburg.

\section{Measures}

The scales used to measure construct items were derived from the literature and all processes followed in the study were based on precedent of other research. The origins of the measures are now explained.

\section{Cultural intelligence}

The CI scale is a 20-item measure drawn from Ang et al. (2004). The measure consists of four subscales that measure the premise of $\mathrm{CI}$, namely metacognitive (4 items, alpha $(\alpha)=0.80)$, cognitive (6 items, $\alpha=0.82$ ), motivational (5 items, $\alpha=0.76$ ) and behavioural ( 5 items, $\alpha=0.78$ ) (Ang et al. 2004, 2007; Van Dyne et al. 2008). The responses of the four dimensions are formed from five-point agree-disagree Likert scales, where higher score rates signify an individual with greater levels of CI (Ang et al. 2006; Ward et al. 2011).

\section{Sociocultural adaptation scale}

Sociocultural adaptation was examined with the use of Ward \& Kennedy's (1999) sociocultural adaptation scale (SCAS). This 23-item scale assesses the level of difficulty an individual experiences when negotiating in day-to-day scenarios in the new cultural setting (i.e. making new friends, one's ability to make themselves understood shopping etc.). The scale uses a five-point rating system with higher scores indicating an individual who experiences greater adaptation challenges (Ward \& Kennedy 1993; Ward \& Rana-Deuba 1999). Ward and Kennedy (1999) stated a median Cronbach's alpha score of 0.86 across 16 cross-sectional samples.

Student performance was taken as an average of self-reported assessment marks. These marks were in percentage form. Gender was measured as a binary variable. Age was measured in years. Language ability was measured as a four-point Likert type scale item. Years in the country was measured as a ratio item in years. Dependent children was measured as the number of dependent children of a respondent. 
TABLE 1: Descriptive statistics.

\begin{tabular}{|c|c|c|c|c|c|}
\hline Variable & Observations & Mean & Standard deviation & Minimum & Maximum \\
\hline Gender & 263 & 0.64 & 0.48 & 0.0 & 1.00 \\
\hline Age & 263 & 24.30 & 6.00 & 18.0 & 58.00 \\
\hline Language ability & 263 & 3.52 & 0.63 & 1.0 & 4.00 \\
\hline Years in South Africa & 263 & 5.08 & 3.51 & 1.0 & 21.00 \\
\hline Children & 259 & 0.25 & 0.80 & 0.0 & 5.00 \\
\hline Metacognitive cultural intelligence & 263 & 5.40 & 0.93 & 1.0 & 7.00 \\
\hline Motivational cultural intelligence & 263 & 5.55 & 0.91 & 1.4 & 7.00 \\
\hline Behavioural cultural intelligence & 263 & 4.73 & 1.26 & 1.0 & 7.00 \\
\hline Cultural adaptation & 263 & 2.12 & 0.57 & 1.0 & 4.24 \\
\hline
\end{tabular}

Source: Authors' own work

\section{Results}

Table 1 reports the descriptive statistics. Of the CI items, behavioural CI was the highest in self-report values, with cognitive CI being the lowest. On average, international students were found to have been in the country for just over 5 years.

Table 2 reports the percentage of international students from different national origins. The largest group within the sample was from Zimbabwe (33\%), followed by Nigeria (18.6\%). A confirmatory factor analysis (CFA) (Mahembe \& Engelbrecht 2014) was performed to assess the fit of the CI constructs as well as the CA items. SPSS Amos was used for this process. The full model, with all respondents included, was used for this testing process. For the CI analysis (Chisquared $=1241.714 ; p<0.001$; degrees of freedom $=584)$, the model had a comparative fit index (CFI) value of 0.809 and a root mean square error of approximation (RMSEA) value of 0.046, suggesting an acceptable fit for the model (Byrne 2010). For the CA scale (Chi-squared $=1195.067 ; p<0.0001$; degrees of freedom $=377$ ), the CFI value was 0.581 and the RMSEA value was 0.09 , suggesting less of a good fit than the $\mathrm{CI}$ model, but given that this latent variable was based on 29 observed items, the CFA values were taken to be acceptable. The specifications of the estimations were derived from theory (discussed in previous sections).

Variables were checked for skewness and kurtosis. Kurtosis assesses the height and sharpness of the tails of a distribution set (Brown 2015). Two values were found in excess of +3 . To address further issues of non-normality in the data, estimations of the specifications also included bootstrapped estimates, which provided confidence intervals with regard to significant effects. In order to address outliers prior to estimation, standardised residuals were calculated, and 15 values were identified with values over the absolute cut-off value of 2 for equation (1), which were removed. In testing the second specification (equation 2), seven outliers were found, and removed.

$$
\begin{aligned}
C A_{i} & =a_{i}+\beta_{1} \text { Gender }_{i}+\beta_{2} \text { Age }_{i}+\beta_{3} \text { Language }_{i} \\
& +\beta_{4} \text { YearsinSA }_{i}+\beta_{5} \text { Children }_{i}+\beta_{6} \text { metacog }_{i} \\
& +\beta_{7} \operatorname{cog}_{i}+\beta_{8} \text { mot }_{i}+\beta_{9} \text { beh }_{i}+u_{i}
\end{aligned}
$$

TABLE 2: Country of origin.

\begin{tabular}{lccc}
\hline Country & $\boldsymbol{N}$ & Percentage & Accumulated Percentage \\
\hline Nigeria & 49 & 18.6 & 18.6 \\
Zimbabwe & 89 & 33.0 & 52.4 \\
Lesotho & 13 & 4.9 & 57.3 \\
Congo & 11 & 4.3 & 61.6 \\
Kenya & 10 & 3.0 & 65.4 \\
Zambia & 9 & 3.4 & 68.8 \\
France & 8 & 3.1 & 71.9 \\
Botswana & 8 & 3.1 & 75.0 \\
Other & 66 & 25.0 & 100.0 \\
\hline
\end{tabular}

Source: Authors' own work

$N$, number.

The variables included in these estimations, and their derivation from the literature, were discussed previously. In equation (1), gender is a binary variable, with male scored as 1 and female as 0 . Age is the age of the individual in years, language is a measure of language ability, scored as a Likert item. Years in SA measures years spent in the country. Children represent the number of children a respondent has. The megacog item represents the metacognitive dimension of SA, $\operatorname{cog}$ representing the cognitive dimension, mot the motivational dimension and beh the behavioural dimension. The outcome variable, CA, represents SA. In equation (2), the variables are the same, except for the outcome variable, Per, which represents student performance.

$$
\begin{aligned}
\text { Per }_{i} & =a_{i}+\beta_{1} \text { Gender }_{i}+\beta_{2} \text { Age }_{i}+\beta_{3} \text { Language }_{i} \\
& +\beta_{4} \text { YearsinSA }_{i}+\beta_{5} \text { Children }_{i}+\beta_{6} \text { metacog }_{i} \\
& +\beta_{7} \operatorname{cog}_{i}+\beta_{8} \text { mot }_{i}+\beta_{9} \text { beh }_{i}+\beta_{10} \text { CA }_{i}+u_{i}
\end{aligned}
$$

The results of this process of testing are reported in Table 2. The first specification (equation 1) was found to have an adjusted $R$-squared value of 0.0985 , suggesting that the variables included explained almost $10 \%$ of the variance in SA. According to the Breusch-Pagan and Cook-Weisberg test for heteroscedasticity, the model was taken to be sufficiently homoskedastic (Chisquare $=1.07 ; p<0.3007$ ), which was supported by the Cameron and Trivedi test (Chi-square $=59.21 ; p<0.2594)$. The Ramsey's RESET test $(F=0.57 ; p<0.6343)$ for model specification suggested no omitted variables. This result was supported by the link test, where the hat-squared value was not significant $(p$ $<0.729)$. The multicollinearity measures were taken to suggest multicollinearity was not a threat to the interpretation of the results, as the mean variance inflation factor (VIF) value for the 
model was 1.41. The highest VIF value within the model was that for age, at 1.85 .

For the second equation, the adjusted R-squared value was 0.2022 , with about a fifth of the variance in student performance explained by the predictors. According to the Breusch-Pagan and Cook-Weisberg test for heteroscedasticity, the model met the basic requirements for homoskedasticity (Chi-square $=0.27 ; p<0.6044$ ), which was supported by the Cameron and Trivedi test (Chi-square $=59.94 ; p<0.5505)$. According to Ramsey's RESET test, this model specification was robust to misspecification $(F=0.96 ; p<0.4141)$ statistically suggesting no omitted variables. This result was supported by the link test, where the hat-squared value was not significant $(p<0.261)$. These results supported the specification of equation (2). Multicollinearity was taken to not be a threat to the interpretation of the results, as the VIF value for the model was 1.56. The highest VIF value within the model was that for age, at 2.24. Table 3 reports the results of the testing of determinant of SA and student performance.

Hypothesis 1: Cultural intelligence is positively and significantly associated with sociocultural adaptation.

The significant association between motivational CI and SA, which is supported by bootstrapped confidence intervals, is in line with other literature that has linked CA and task performance, (Ang \& Van Dyne 2015; Ang et al. 2007; Huff et al. 2014; Kodwani 2012). More specifically, the significance of this association supports Ang et al.'s (2007) findings, where
CI was positively related to two aspects of SA, namely cultural adjustment, performance and the well-being of a sojourner (Ang et al. 2007). However, it is only motivational CI that is significant here, whereas in Ang et al.'s (2007) study, both motivational and behavioural CI were found to be associated with SA. Cognitive, metacognitive and behavioural CI are not significant (Table 2). The negative association reflects a reduction in the challenges associated with CA, and motivational $\mathrm{CI}$ is therefore taken to have a positive effect on SA in this context. According to further t-test results, no significant difference was found in SA by gender, which is in line with the non-significance of the gender variable in OLS testing. The positive relationship between cross-cultural adjustment and motivational CI is typically ascribed to the high levels of intrinsic interest in other cultures which in turn increase the possibility of succeeding within various cultural settings (DeNisi \& Pritchard 2006; Eccles \& Wigfield 2002; Stone-Romero et al. 2003; Templer et al. 2006). What is encouraging here is that someone with a motivation to learn about another culture can have significantly better sociocultural adjustment in this context. Years in the country was also found to be associated with better SA. This may be as a result of improved knowledge of the conventions and legal, economic and social systems of South Africa which improve environmental adaptation (Triandis 1994). It is possible that an individual's motivational attitude and interest in other cultures dominate in the SA in this country environment, as it enables investments into the SA process.

TABLE 3: Determinants of sociocultural adaptation and performance.

\begin{tabular}{|c|c|c|c|c|}
\hline \multirow[b]{2}{*}{ VARIABLES } & (1) & (2) & (3) & (4) \\
\hline & $\begin{array}{l}\text { Sociocultural adaptation Ordinary } \\
\text { Least Squares }\end{array}$ & $\begin{array}{c}\text { Sociocultural adaptation } \\
\text { Bootstrapped confidence intervals }\end{array}$ & $\begin{array}{c}\text { Student performance Ordinary } \\
\text { Least Squares }\end{array}$ & $\begin{array}{l}\text { Student performance Bootstrapped } \\
\text { confidence intervals }\end{array}$ \\
\hline \multirow[t]{2}{*}{ Gender } & 0.434 & 0.434 & 0.490 & 0.490 \\
\hline & (1.915) & $(1.803)$ & (1.686) & (1.769) \\
\hline \multirow[t]{2}{*}{ Age } & 0.0658 & 0.0658 & $0.731 * * *$ & $0.731 * * *$ \\
\hline & $(0.212)$ & (0.197) & $(0.217)$ & $(0.212)$ \\
\hline \multirow[t]{2}{*}{ Language ability } & 1.609 & 1.609 & 0.610 & 0.610 \\
\hline & $(1.423)$ & $(1.412)$ & $(1.307)$ & (1.311) \\
\hline \multirow[t]{2}{*}{ Years in the country } & $-0.892 * * *$ & $-0.892^{* * *}$ & -0.0189 & -0.0189 \\
\hline & $(0.275)$ & $(0.280)$ & $(0.200)$ & $(0.170)$ \\
\hline \multirow[t]{2}{*}{ Children } & 1.855 & 1.855 & $-5.641 * * *$ & $-5.641 * * *$ \\
\hline & (1.435) & (1.395) & $(1.653)$ & $(1.606)$ \\
\hline \multirow[t]{2}{*}{ Metacognitive } & -1.352 & -1.352 & $1.989 * *$ & $1.989 * *$ \\
\hline & (1.155) & (1.168) & $(0.856)$ & $(0.956)$ \\
\hline \multirow[t]{2}{*}{ Cognitive } & -0.734 & -0.734 & 0.162 & 0.162 \\
\hline & $(0.911)$ & $(1.087)$ & $(0.808)$ & (0.849) \\
\hline \multirow[t]{2}{*}{ Motivation } & $-2.526 * *$ & $-2.526 * *$ & 1.452 & $1.452 *$ \\
\hline & (1.189) & $(1.269)$ & $(0.890)$ & $(0.842)$ \\
\hline \multirow[t]{2}{*}{ Behavioural } & -0.784 & -0.784 & $-1.278^{*}$ & $-1.278^{*}$ \\
\hline & $(0.816)$ & $(1.032)$ & $(0.686)$ & $(0.713)$ \\
\hline \multirow[t]{2}{*}{ Sociocultural adaptation } & - & - & $0.0853^{*}$ & $0.0853^{*}$ \\
\hline & & & $(0.0441)$ & $(0.0447)$ \\
\hline \multirow[t]{2}{*}{ Constant } & $84.69 * * *$ & $84.69 * * *$ & $29.86 * * *$ & $29.86 * * *$ \\
\hline & (9.375) & $(9.065)$ & $(8.263)$ & $(8.340)$ \\
\hline Observations & 247 & 247 & 109 & 109 \\
\hline R-squared & 0.131 & 0.131 & 0.276 & 0.276 \\
\hline
\end{tabular}

Source: Authors' own work

Standard errors in parentheses.

$* * *, p<0.01 ; * *, p<0.05 ; *, p<0.1$ 
Hypothesis 2: Sociocultural adaptation is positively and significantly associated with student performance.

The positive association between SA and student performance is in line with previous research which has also found these relationships (Ang et al. 2007; Rienties et al. 2012; Ward, Wilson \& Fischer 2011). According to Ogbu and Simons (1998), there may be other forces that have an effect on academic performance over and above SA. Research has shown that the characteristics of an individual (i.e. gender, socioeconomic background and familial cultural capital) can also have a large effect on the academic performance of an international student (Glick \& Hohmann-Marriott 2007; Nijenhuis et al. 2004), and the negative relationship between children and academic performance, as well as the positive relationship between age and performance, support previous research findings in this regard.

Interestingly, language ability was not found to predict CA nor student performance. This finding differs from previous research, such as that by Capps et al. (2005) which found English proficiency to be related to educational achievement of international students. Further tests were performed without covariates, and this association was not significant in these tests either. The implication of this is that the CA or CI items were not the reason for the non-significance of this effect in tested specifications.

In terms of the CI items, the metacognitive and motivational dimensions were found to be significant predictors of student performance (the significance of the latter confirmed by bootstrapped confidence intervals). Given that motivational $\mathrm{CI}$ is also significantly associated with SA, it was considered possible that the contribution of motivational CI to student performance might work through the SA channel. This potentiality was tested using Hypothesis 3. Metacognitive CI was not found to predict SA, however, and the contribution of metacognitive CI to student performance was therefore taken to not be via the SA channel. It is possible that the metacognitive cognitions allowing for deep information processing in relation to culture (Flavell 1979; Rose et al. 2010) might also have other information processing benefits for academic performance. Further research should apply qualitative, or causal, methods to understand the causal relationships that underlie these findings.

The behavioural CI dimension, however, was found to be a negative predictor of student performance. Given low levels of multicollinearity in the tested models, these results were taken to suggest different channels of influence for CI on student performance. The capability to engage in adaptive behaviours related to specific cultural settings (Ramsey \& Lorenz 2016; Rose et al. 2010) is expected to be associated with SA, but the lack of an association between behavioural $\mathrm{CI}$ and SA suggests that the negative association between behavioural $\mathrm{CI}$ and academic performance is not related to the SA process, but to some other effect. It is difficult to understand how lower levels of behavioural CI are associated with better academic performance of international students, and this is left for further research to investigate the causal mechanisms that could account for this relationship.

Hypothesis 3: Sociocultural adaptation mediates the relationship between cultural intelligence and academic performance.

According to bootstrapped OLS tests of mediation using Baron and Kenny's (1986) process, SA was not found to mediate the relationships between CI and academic performance. All four dimensions were tested. The implication of this result is that the contribution of metacognitive, motivational and behavioural CI to academic performance might not necessarily be through the SA channel. The lack of a mediation relationship between motivational CI and student performance with SA not included as a covariate suggests that motivational $\mathrm{CI}$ has both a direct and indirect relationship (through SA) with student performance. This suggests that the influence of motivational CI might also work to contribute to academic performance through both the SA channel and other channels. It is possible that a positive attitudinal CI motivation might also be associated with beneficial motivational effects that also enable academic performance. Motivational effects are not expected to act in a silo.

Hypothesis 4: Sociocultural adaptation is significantly associated with academic performance.

Sociocultural adaptation was found to be significantly associated with international student performance (Table 4), as predicted by the literature (Crowne 2008; Phillion 2002). According to these results, it is possible that of the four CI dimensions only motivational CI has an indirect effect on student performance through SA. This suggests that SA is only one aspect of the contribution of CI to student performance. Nevertheless, these results suggest that SA can contribute to academic performance, and it is recommended that universities actively undertake to provide support for the SA of international students. Having reported and discussed the results of the study, conclusions and recommendations for theory and practice are now considered.

\section{Ethical considerations}

An ethics certificate was obtained from the Ethics Committee of the School of Economic and Business Sciences of the University of the Witwatersrand (Protocol Number CBUSE/1132).

\section{Conclusions and recommendations for theory and practice}

The objective of this study was to test theory which predicts that CI endowments contribute to SA and student performance in the context of a large South African university. Knowledge of the differential contributions of different CI dimensions to SA was considered particularly important, as they work to empower adaptation through different mechanisms. Further mediation estimations were applied to test the extent to which the different CI dimensions contribute both indirectly and directly to student performance and whether the channel 


\section{Hypothesis}

Hypothesis 1.1. Metacognitive cultural intelligence is positively and significantly associated with sociocultural adaptation

Hypothesis 1.2. Cognitive cultural intelligence is positively and significantly associated with sociocultural adaptation

Hypothesis 1.3. Motivational cultural intelligence is positively and significantly associated with sociocultural adaptation

Null hypothesis not rejected

Null hypothesis not rejected

Hypothesis 1.4. Behavioural cultural intelligence is positively and significantly associated with sociocultural adaptation

Null hypothesis rejected

Hypothesis 2.1. Metacognitive cultural intelligence is positively and significantly associated with academic performance

Null hypothesis not rejected

Hypothesis 2.2. Cognitive cultural intelligence is positively and significantly associated with academic performance

Hypothesis 2.3. Motivational cultural intelligence is significantly associated with academic performance

Hypothesis 2.4. Behavioural cultural intelligence is positively and significantly associated with academic performance

Hypothesis 3.1. Sociocultural adaptation mediates the relationship between metacognitive cultural intelligence and academic performance of international students

Hypothesis 3.2. Sociocultural adaptation mediates the relationship between cognitive cultural intelligence and academic performance of international students

Hypothesis 3.3. Sociocultural adaptation mediates the relationship between motivational cultural intelligence and academic performance of international students

Hypothesis 3.4. Sociocultural adaptation mediates the relationship between behavioural cultural intelligence and academic performance of international students

Hypothesis 4. Sociocultural adaptation is significantly associated with student performance

Null hypothesis rejected

Null hypothesis not rejected

Null hypothesis rejected

Null hypothesis rejected

Null hypothesis not rejected

Null hypothesis not rejected

Null hypothesis not rejected

Null hypothesis not rejected

Null hypothesis rejected

\section{Source: Authors' own work}

through which these effects flow is related to SA. Results suggest that only motivational CI contributes to SA in this context, and motivational $\mathrm{CI}$ is therefore the only CI dimension that contributes both to SA as well as to student performance. Tests for mediation failed to confirm a substantial decrease in the direct effect when the indirect effect was included in testing. It was concluded that motivational CI may be unique among the CI dimensions in that it contributes to SA and to student performance. This knowledge is taken to be important for university administrators, as individuals with higher motivational CI might be more likely to self-identify themselves for support because of their higher interest in acculturation. If administrators can incentivise or motivate international students to be involved in university activities, student performance might be enabled through the SA channel. The strong negative association between dependent children and student performance for international students suggests that childcare support by the university might help improve the performance of these students. Although years in the country was found to be positively related to SA, it was not found to be associated with student performance. This broadly suggests that adjustment to the country may not account for variance in student performance. International students who have arrived more recently seem to not be at a disadvantage compared to those who have been in the country for longer. Older international students seem to have a performance advantage over younger sojourners. University support to international students should perhaps take the form of programmes that seek more specific input from the students themselves. Further research should apply qualitative methods, and particularly causal methods to explain the causal mechanisms and channels that underlie these findings.

In conclusion, with the increasing number of students migrating over cultural borders for higher education purposes, the concept of cross-cultural competence becomes an important issue in the successful acculturation of international students. As a means of establishing an 'internationally friendly' university environment, it is important for managers in universities to develop ways to facilitate the development of international students' crosscultural competence, as this may improve the academic performance of sojourners.

This study adds to the CI literature by introducing new knowledge about CI in the South African context, and its role in enabling SA as well as its different relationships with sojourner academic performance. Importantly, the results show that there is a relationship between the level of adaptation individuals have and their academic performance. Managers in academic institutions may need to be vigilant when it comes to how well their international students are adjusting to their new cultural settings, as this may be supported through establishing programmes dedicated to assisting sojourners with being more culturally aware and developing their multicultural competence in order to adjust better to their new cultural setting. This may be particularly important given the longstanding xenophobic climate in South Africa (Callaghan 2014).

Future research should consider collecting longitudinal data. The use of a longitudinal sample, from different universities across South Africa, would allow for more results that could be generalised across the national context, allowing for a more holistic perspective of the SA of international students within and across the country. It is acknowledged that the findings of this study might generalise only to those institutions that share similar contextual and institutional characteristics. It is important to stress that these findings are relevant to the South African and broader African context but may not necessarily generalise to other contexts.

\section{Acknowledgements}

We would like to thank the useful insights provided by the anonymous reviewers, which enabled us to improve the work. 


\section{Competing interests}

The authors declare that they have no financial or personal relationships that may have inappropriately influenced them in writing this article.

\section{Authors' contributions}

T.M.M. conceptualised the research and provided conceptual input and statistical analysis. C.W.C. provided conceptual input and statistical analysis and also contributed to the final write-up.

\section{References}

Amaratunga, D., Baldry, D., Sarshar, M. \& Newton, R., 2002, 'Quantitative and qualitative research in the built environment: Application of "mixed" research approach', WorkStudy51(1),17-31.https://doi.org/10.1108/00438020210415488

Andrade, M.S., 2006, 'International students in English-speaking universities adjustment factors', Journal of Research in International Education 5(2), 131-154. https://doi.org/10.1177/1475240906065589

Ang, S. \& Van Dyne, L.C., 2015, Handbook of cultural intelligence, Sharpe, New York.

Ang, S., Van Dyne, L.C., Koh, C., Ng, K.Y., Templer, K.J., Tay, C. et al., 2007, 'Cultural intelligence: Its measurement and effects on cultural judgment and decision
making, cultural adaptation and task performance', Management and making, cultural adaptation and task performance, Management and
Organization Review 3(3), 335-371. https://doi.org/10.1111/j.1740-8784.2007. Organizatio
$00082 . x$

Ang, S., Van Dyne, L.C. \& Ng, K.Y., 2004, 'The measurement of cultural intelligence', in Academy of Management Meetings Symposium on Cultural Intelligence in the 21st Century, New Orleans, LA, 6th-11th August.

Bandura, A., 2002, 'Social cognitive theory in cultural context', Applied Psychology 51(2), 269-290. https://doi.org/10.1111/1464-0597.00092

Baron, R.M. \& Kenny, D.A., 1986, 'The moderator-mediator variable distinction in social psychological research: Conceptual, strategic, and statistical considerations' Journal of Personality and Social Psychology 51(6), 1173. https://doi.org/ 10.1037/0022-3514.51.6.1173

Bhaskar-Shrinivas, P., Harrison, D.A., Shaffer, M.A. \& Luk, D.M., 2005, 'Input-based and time-based models of international adjustment: Meta-analytic evidence and theoretical extensions', Academy of Management Journal 48(2), 257-281. https:// doi.org/10.5465/AMJ.2005.16928400

Bhawuk, D.P., Sakuda, K.H. \& Munusamy, V.P., 2008, 'Intercultural competence development and triple-loop cultural learning', in S. Ang \& L. Van Dyne (eds.) Handbook of Cultural Intelligence: Theory, measurement, and applications, $\mathrm{pp}$ 342-355, M.E. Sharp, Armonk.

Black, J.S., 1990, 'Factors related to the adjustment of Japanese expatriate managers in America', in G.R. Ferris (ed.), Research in personnel and human resources management, pp. 109-125, JAl Press, Greenwich.

Brislin, R., Worthley, R. \& Macnab, B., 2006, 'Cultural intelligence understanding behaviors that serve people's goals', Group \& Organization Management 31(1) 40-55. https://doi.org/10.1177/1059601105275262

Brown, S., 2015, Measures of shape: Skewness and kurtosis, viewed 22 May 2015, from http://brownmath.com/stat/shape.htm.

Byrne, B.M., 2010, Structural equation modeling with Amos: Basic concepts, applications, and programming, 2nd edn., Taylor and Francis Group, New York.

Caligiuri, P. \& Tarique, I., 2009, 'Predicting effectiveness in global leadership activities', Journal of World Business 44(3), 336-346. https://doi.org/10.1016/j.jwb.2008. 11.005

Callaghan, C.W., 2014, 'Changes in the structure of earnings of informal street traders', Acta Commercii 14(1), 1-13. https://doi.org/10.1016/j.jwb.2008.11.005

Callaghan, C.W., 2015, 'Values infections and the epidemiology of values: Implications for management', Management Dynamics 24(3), 33-46.

Capps, R., Fix, M., Ost, J., Reardon-Anderson, J. \& Passel, J.S., 2005, The health and well-being of young children of immigrants, viewed 30 March 2017, from http:// www.urban org/sites/default/files/publication/51501/311139-The-Health-andWell-Being-of-Young-Children-of-Immigrants.PDF

Chen, A.S.Y., Wu, I.H. \& Bian, M.D., 2014, 'The moderating effects of active and agreeable conflict management styles on cultural intelligence and cross-cultura adjustment', International Journal of Cross Cultural Management 14(3), 270-288. https://doi.org/10.1177/1470595814525064

Chen, S., 2009, 'A study of international students' life situation - A case study of the international students in University of Twente', unpublished master's thesis, University of Twente, Enschede, The Netherlands, viewed 04 November 2017 from http://essay.utwente.nl/60378/1/MSc_Sheng-He_Chen.pdf.

Chirkov, V., Vansteenkiste, M., Tao, R. \& Lynch, M., 2007, 'The role of self-determined motivation and goals for study abroad in the adaptation of international students' International Journal of Intercultural Relations 31, 199-222. https://doi.org/ 10.1016/j.ijintrel.2006.03.002

Council of Higher Education (CHE), 2009, Higher education monitor No 7: Postgraduate studies in South Africa: A statistical profile, Council of Higher Education, Pretoria.
Crowne, K.A., 2008, 'What leads to cultural intelligence', Business Horizons 51, $391-$ 399. https://doi.org/10.1016/j.bushor.2008.03.010

Crowne, K.A., 2013, 'Cultural exposure, emotional intelligence, and cultural intelligence an exploratory study', International Journal of Cross Cultural Management 13(1), 5-22. https://doi.org/10.1177/1470595812452633

Cushner, K. \& Karim, A.U., 2004, 'Study abroad at the university level', Handbook of Intercultural Training 3, 289-308. https://doi.org/10.4135/9781452231129.n12

Deci, E.L. \& Ryan, R.M., 1985, 'The general causality orientations scale: Selfdetermination in personality', Journal of Research in Personality 19(2), 109-134. https://doi.org/10.1016/0092-6566(85)90023-6

DeNisi, A.S. \& Pritchard, R.D., 2006, 'Performance appraisal, performance management and improving individual performance: A motivational framework', Management and Organization Review 2(2), 253-277.

Earley, P.C. \& Ang, S., 2003, Cultural intelligence: Individual interactions across cultures, Stanford University Press, Stanford, CA

Earley, P.C., Ang, S. \& Tan, J.S., 2006, CQ: Developing cultural intelligence at work, Stanford University Press, Stanford, CA.

Earley, P.C. \& Peterson, R.S., 2004, 'The elusive cultural chameleon: Cultural intelligence as a new approach to intercultural training for the global manager', Academy of Management Learning \& Education 3(1), 100-115. https://doi. org/10.5465/AMLE.2004.12436826

Eccles, J.S. \& Wigfield, A., 2002, 'Motivational beliefs, values, and goals', Annua Review of Psychology 53(1), 109-132. https://doi.org/10.1146/annurev.psych.53. 100901.135153

Epel, E.S., Bandura, A. \& Zimbardo, P.G., 1999, 'Escaping homelessness: The influences of self-efficacy and time perspective on coping with homelessness', Journal of Applied Social Psychology 29(3), 575-596. https://doi.org/10.1111/j.1559-1816. 1999.tb01402.x

Flavell, J.H., 1979, 'Metacognition and cognitive monitoring: A new area of cognitivedevelopmental inquiry', American Psychologist 34(10), 906. https://doi. org/10.1111/j.1559-1816.1999.tb01402.x

France, C., 2013, La mobilité des étudiants d'Afrique sub-saharienne et du Maghreb, viewed 05 November 2017, from http://ressources.campusfrance.org/publi institu/etude_prospect/mobilite_continent/fr/note_07_hs_fr.pdf

Friedman, T.L., 2005, 'It's a flat world, after all', The New York Times 3 April, 33-37.

Gelfand, M.J., Erez, M. \& Aycan, Z., 2007, 'Cross-cultural organizational behavior', Annual Review of Psychology 58, 479-514. https://doi.org/10.1146/annurev. psych.58.110405.085559

Glick, J.E. \& Hohmann-Marriott, B., 2007, 'Academic performance of young children in immigrant families: The significance of race, ethnicity, and national origins', International Migration Review 41(2), 371-402. https://doi.org/10.1111/j. 1747-7379.2007.00072.x

Healy, M. \& Perry, C., 2000, 'Comprehensive criteria to judge validity and reliability of qualitative research within the realism paradigm', Qualitative Market Research 3(3), 118-126. https://doi.org/10.1108/13522750010333861

Hofstede, G., 2001, Culture's consequences: Comparing values, behaviors, institutions and organizations across nations, 2nd edn., Sage, Thousand Oaks, CA.

Huff, K.C., 2013, 'Language, cultural intelligence and expatriate success', Managemen Research Review 36(6), 596-612. https://doi.org/10.1108/01409171311325750

Huff, K.C., Song, P. \& Gresch, E.B., 2014, 'Cultural intelligence, personality, and crosscultural adjustment: A study of expatriates in Japan', International Journal of Intercultural Relations 38,151-157. https://doi.org/10.1016/j.ijintrel.2013.08.005

Hunt, S.D., 1991, 'Positivism and paradigm dominance in consumer research: Toward critical pluralism and rapprochement', Journal of Consumer Research 18(1), 3244. https://doi.org/10.1086/209238

ICEF Monitor, 2013, South Africa an important regional hub for international students, ICEF Monitor, viewed 30 March 2017, from http://monitor.icef.com/2013/11/ south-africa-an-important-regional-hub-for-international-students/

Johnson, J.P., Lenartowicz, T. \& Apud, S., 2006, 'Cross-cultural competence in international business: Toward a definition and a model', Journal of International Business Studies 37(4), 525-543.

Kerlinger, F.N., 1986, Foundations of behavioral science, Holt, Rinehart, and Winston, New York.

Kodwani, A.E., 2012, 'Beyond emotional intelligence (EQ): The role of cultura intelligence (CQ) on cross-border assignment', World Review of Business Research 2(4), 86-102.

Kurpis, L.H. \& Hunter, J., 2016, 'Developing students' cultural intelligence through an experiential learning activity: A cross-cultural consumer behavior interview', Journal of Marketing Education 39(1), 30-46.

Lam, H. \& Selmer, J., 2004, "Are former "third-culture kids" the ideal business expatriates?', Career Development International 9(2), 109-122. https://doi. org/10.1108/13620430410526166

Leung, K., Ang, S. \& Tan, M.L., 2014, 'Intercultural competence', Annual Review of Organizational Psychology and Organizational Behavior 1(1), 489-519. https:// doi.org/10.1146/annurev-orgpsych-031413-091229

Lin, Y.C., Chen, A.S.Y. \& Song, Y.C., 2012, 'Does your intelligence help to survive in a foreign jungle? The effects of cultural intelligence and emotional intelligence on cross-cultural adjustment', International Journal of Intercultural Relations 36(4), 541-552. https://doi.org/10.1016/j.ijintrel.2012.03.001

MacNab, B.R., 2012, 'An experiential approach to cultural intelligence education' Journal of Management Education 36(1), 66-94. https://doi.org/10.1177/ 1052562911412587 
Mahembe, B. \& Engelbrecht, A.S., 2014, 'A preliminary study to assess the construct validity of a cultural intelligence measure on a South African sample', SA Journal of Human Resource Management 12(1), 8. https://doi.org/10.4102/sajhrm. v12i1.558

Malek, M.A. \& Budhwar, P., 2013, 'Cultural intelligence as a predictor of expatriate adjustment and performance in Malaysia', Journal of World Business 48(2), 222231. https://doi.org/10.1016/j.jwb.2012.07.006

Mendenhall, M. \& Oddou, G., 1985, 'The dimensions of expatriate acculturation: A review', Academy of Management Review 10(1), 39-47.

Misra, R. \& Castillo, L.G., 2004, 'Academic stress among college students: Comparison of American and international students', International Journal of Stress Management 11(2), 132. https://doi.org/10.1037/1072-5245.11.2.132

Ng, K.Y. \& Earley, P.C., 2006, 'Culture + intelligence: Old constructs, new frontiers', Group \& Organization Management 31(1), 4-19. https://doi.org/10.1177/ 1059601105275251

Nijenhuis, J., Tolboom, E., Resing, W. \& Bleichrodt, N., 2004, 'Does cultural background influence the intellectual performance of children from immigrant groups? The RAKIT intelligence test for immigrant children', European Journal of Psychological Assessment 20(1), 10-26.

Papageorgiou, E. \& Callaghan, C.W., 2014, 'Resource scarcity and information technology: Issues and trends among first-year accounting students', South African Journal of Higher Education 28(5), 1575-1592.

Phillion, J., 2002, 'Becoming a narrative inquirer in a multicultural landscape', Journal of Curriculum Studies 34(5), 535-556. https://doi.org/10.1080/00220270 110108204

Poyrazli, S. \& Grahame, K.M., 2007, 'Barriers to adjustment: Needs of international students within a semi-urban campus community', Journal of Instructional Psychology 34(1), 28-46.

Ramsey, J.R. \& Lorenz, M.P., 2016, 'Exploring the impact of cross-cultural management education on cultural intelligence, student satisfaction, and commitment', Academy of Management Learning \& Education 15(1), 79-99. https://doi. org/10.5465/amle.2014.0124

Remenyi, D., Williams, B., Money, A. \& Swartz, E, 1998, Doing research in business and management: An introduction to process and method, Sage, London.

Rienties, B., Beausaert, S., Grohnert, T., Niemantsverdriet, S. \& Kommers, P., 2012 'Understanding academic performance of international students: The role of ethnicity, academic and social integration'. Higher Education 63(6), 685-700. https://doi.org/10.1007/s10734-011-9468-1

Rose, R.C., Ramalu, S.S., Uli, J. \& Kumar, N., 2010, 'Expatriate performance in international assignments: The role of cultural intelligence as dynamic intercultural competency', International Journal of Business and Management 5(8), 76-85.

Schreuders-van den Bergh, R. \& Du Plessis, Y., 2016, 'Exploring the role of motivational cultural intelligence in SIE women's adjustment', Journal of Global Mobility 4(2) 131-148. https://doi.org/10.1108/JGM-02-2016-0003

Searle, W. \& Ward, C., 1990, 'The prediction of psychological and sociocultural adjustment during cross-cultural transitions', International Journal of Intercultural Relations 14(4), 449-464. https://doi.org/10.1016/0147-1767(90)90030-Z

Shaffer, M.A., Harrison, D.A., Gregersen, H., Black, J.S. \& Ferzandi, L.A., 2006, 'You can take it with you: Individual differences and expatriate effectiveness', Journal of Applied Psychology 91(1), 109. https://doi.org/10.1037/00219010.91.1.109
Sherry, M., Thomas, P. \& Chui, W.H., 2010, 'International students: A vulnerable student population', Higher Education 60(1), 33-46. https://doi.org/10.1007/ student population,

Stone Romero, E.F., Stone, D.L. \& Salas, E., 2003, 'The influence of culture on role conceptions and role behavior in organisations', Applied Psychology 52(3), 328362. https://doi.org/10.1111/1464-0597.00139

Templer, K.J., Tay, C. \& Chandrasekar, N.A., 2006, 'Motivational cultural intelligence, realistic job preview, realistic living conditions preview, and cross-cultura adjustment', Group \& Organization Management 31(1), 154-173. https://doi. org/10.1177/1059601105275293

Triandis, H.C., 1994, Culture and social behavior, McGraw-Hill, New York.

Van Dyne, L., Ang, S. \& Koh, C., 2008, 'Development and validation of the CQS: The cultural intelligence scale', in S. Ang \& L. Van Dyne (eds.), Handbook of cultural intelligence: Theory, measurement and applications, pp. 16-40, M.E. Sharp, Armonk.

Wang, K.T., Heppner, P.P., Wang, L. \& Zhu, F., 2015, 'Cultural intelligence trajectories in new international students: Implications for the development of cross-cultural competence', International Perspectives in Psychology 4(1), 51. https://doi. org/10.1037/ipp0000027

Ward, C. \& Fischer, R., 2008, 'Personality cultural intelligence and cross-cultura adaptation', in S. Ang \& L. Van Dyne (eds.). Handbook of cultural intelligence: Theory, measurement and applications, pp. 159-176, M.E. Sharp, Armonk.

Ward, C. \& Kennedy, A., 1993, 'Where's the "culture" in cross-cultural transition? Comparative studies of sojourner adjustment', Journal of Cross-Cultural Psychology 24(2), 221-249.

Ward, C. \& Kennedy, A., 1996, 'Crossing cultures: The relationship between psychological and sociocultural dimensions of cross-cultural adjustment', in J. Pandey, D. Sinha \& D.P.S. Bhawuk (eds.), Asian contributions to cross-cultural psychology, pp. 289-306, Sage, Thousand Oaks, CA.

Ward, C. \& Kennedy, A., 1999, 'The measurement of sociocultural adaptation' International Journal of Intercultural Relations 23(4), 659-677. https://doi. org/10.1016/S0147-1767(99)00014-0

Ward, C. \& Rana-Deuba, A., 1999, 'Acculturation and adaptation revisited', Journal of Cross-Cultural Psychology 30(4), 422-442. https://doi.org/10.1177/ 0022022199030004003

Ward, C., Wilson, J. \& Fischer, R., 2011, 'Assessing the predictive validity of cultural intelligence over time', Personality and Individual Differences 51(2), 138-142. https://doi.org/10.1016/j.paid.2011.03.032

Westwood, M.J. \& Barker, M., 1990, 'Academic achievement and social adaptation among international students: A comparison groups study of the peer-pairing program', International Journal of Intercultural Relations 14(2), 251-263. https:// doi.org/10.1016/0147-1767(90)90008-K

Williams, C.T \& Johnson, L.R., 2011, 'Why can't we be friends?: Multicultural attitudes and friendships with international students', International Journal of Intercultural Relations 35(1), 41-48. https://doi.org/10.1016/j.ijintrel.2010.11.001

Wilson, G.P., 2011, 'Fitting-in: Sociocultural adaptation of international graduate students', in Northeastern Educational Research Association Conference Proceedings, Rocky Hill, CT, 19th-21st October

Yang, R.P.J., Noels, K.A. \& Saumure, K.D., 2006, 'Multiple routes to cross-cultura adaptation for international students: Mapping the paths between self-construals, English language confidence, and adjustment', International Journal of Intercultural Relations 30(4), 487-506. https://doi.org/10.1016/j.ijintrel.2005. 11.010 